\title{
A STUDY ON THE USE OF A COMBINATION OF MIFEPRIN AND MISOPROSTOL FOR SECOND TRIMESTER TERMINATION OF PREGNANCY
}

\author{
Yellayi Aruna Subha Shree Rao1, Aruna S2, Sarada Bai K3 \\ ${ }^{1}$ Assistant Professor, Department of Obstetrics and Gynaecology, Andhra Medical College, Visakhapatnam. \\ ${ }^{2}$ Assistant Professor, Department of Obstetrics and Gynaecology, Andhra Medical College, Visakhapatnam. \\ 3 Professor and HOD, Department of Obstetrics and Gynaecology, Andhra Medical College, Visakhapatnam.
}

\section{ABSTRACT}

The significant need to conduct second trimester abortions safely is being addressed by the use of a combination of mifepristone and misoprostol, though their dosage regimen continue to be debated. The present study was conducted on 50 selected women in the Department of Gynecology and Obstetrics, Andhra Medical College, Visakhapatnam, from April 2014 to October 2015 to determine the safety and efficacy of $200 \mathrm{mg}$ of mifepristone orally followed $24 \mathrm{hrs}$. later by $400 \mathrm{mcg}$ of misoprostol administered vaginally every 6hrs. upto a maximum of 5 doses, which is the regimen recommended by FOGSI and the results were analysed. The mean induction abortion interval (IAI) was $10.08 \pm 2.9 \mathrm{hrs}$. and $76 \%$ of cases had IAI of $\leq 12 \mathrm{hrs}$. The side effects were few and manageable. Hence, the above regimen should be used for safe and effective termination of a second trimester pregnancy.

\section{KEYWORDS}

Abortion, Mifepristone, Misoprostol, Second trimester.

HOW TO CITE THIS ARTICLE: Yellayi Aruna Subha Shree Rao, Aruna S, Sarada Bai K. "A Study on the use of A Combination of Mifeprin and Misoprostol for Second Trimester Termination of Pregnancy." Journal of Evolution of Medical and Dental Sciences 2015; Vol. 4, Issue 97, December 03; Page: 16210-16212, DOI: 10.14260/jemds/2015/2384

\section{INTRODUCTION}

Abortion is the single most common procedure performed for women worldwide. Second trimester abortions constitute $10-15 \%$ of all induced abortions worldwide, but are responsible for two-thirds of all major abortion-related complications. Medical abortion, the termination of pregnancy through the use of a drug or a combination of drugs has the potential to reduce complications. Though the medical abortions upto nine weeks of gestation were approved in some countries by 1992, the approval for the use of the above drugs for second trimester abortion was obtained in these countries only in 1999-2000. The optimal method of second trimester abortion continues to be debated.

Advantage of medical abortion in second trimester includes the scope for examination of the fetus in abortions done for fetal anomalies to further evaluate the subsequent risk of recurrence and provide information to help in counseling of these patients, which is not possible if dilatation and evacuation is the method chosen.[1] The most commonly used combination is mifepristone taken first and misoprostol administered 24-48 hours later. Mifepristone an antiprogesterone leads to cervical softening, increased uterine sensitivity to prostaglandins and conversion of the quiet pregnant uterus into an organ of spontaneous activity with maximal effect at 36-48 hours. [2] Misoprostol a synthetic PGE-1 analogue induces cervical ripening as well as strong uterine contractions and leads to expulsion of a pregnancy. The oral tablet is effective in different routes of administration and the dose of prostaglandin can be easily adjusted according to need.

Financial or Other, Competing Interest: None.

Submission 11-11-2015, Peer Review 13-11-2015,

Acceptance 24-11-2015, Published 01-12-2015.

Corresponding Author:

Dr. Yellayi Aruna Subha Shree Rao,

Plot No. 113,

MVP Sector 12,

Visakhapatnam- 530017

E-mail: arunay67@hotmail.com

DOI:10.14260/jemds/2015/2384
It is stable at room temperature, is cost effective and has limited effect on the bronchi and blood vessels.

Side effects are dose-dependent, usually mild and selflimiting. [3] Mifepristone and Misoprostol act synergistically in combination and where both are available both should be used. Misoprostol alone should be used in countries where Mifepristone is not available. Pre-treatment with Mifepristone increases success rate, shortens the Induction Abortion Interval (IAI) and reduces the amount of prostaglandins required for second trimester abortion.

During the second trimester due to increased sensitivity of the uterine muscles to prostaglandins, lower doses of misoprostol are sufficient as compared to first trimester. Uterine rupture has been reported in association with medical abortion at late gestation. The risk is less than 1 in 1000. FOGSI ICOG good clinical practice recommendation for second trimester abortion suggests $200 \mathrm{mg}$ mifepristone followed after $36-48 \mathrm{hrs}$. by $400 \mathrm{mcg}$ of misoprostol administered at 3-6hrs. interval upto 5 doses. This study was undertaken to assess the safety and efficacy of the combination of Mifepristone and Misoprostol for second trimester medical abortion following the above guidelines.

\section{MATERIALS AND METHODS}

The present study was conducted in the Department of Gynecology and Obstetrics, Andhra Medical College, Visakhapatnam from April 2014 to October 2015. Women requesting a mid-trimester termination of pregnancy (Between 13 and 20 weeks of pregnancy) were screened for eligibility by interview, clinical examination, and laboratory investigations including determination of the hemoglobin concentration and liver and renal function tests. Duration of pregnancy and viability of the fetus were confirmed by ultrasound scan.

Fifty healthy women who fulfilled the legal criteria for a termination of pregnancy and had a singleton viable pregnancy of 13-20 weeks' duration were included. Exclusion criteria were hypersensitivity to mifepristone and misoprostol, contraindications for the use of the 2 drugs, previous scarred uterus (Cesarean delivery, myomectomy), hemoglobin level below $8 \mathrm{gm} / \mathrm{dl}$ and serious medical diseases such as severe hypertension, uncontrolled diabetes or renal and liver disease. All participants provided a written and 
informed consent. The indications for termination of pregnancy were as per the medical termination of pregnancy rules in India and included fetal anomalies, social and economic factors and pregnancy resulting from contraceptive failure.

All participants received $200 \mathrm{mg}$ of mifepristone orally followed $24 \mathrm{hrs}$. later by $400 \mathrm{mcg}$ of misoprostol every $6 \mathrm{hrs}$., administered vaginally upto a maximum of 5 doses. With the onset of vaginal bleeding misoprostol was administered by the oral route. The cases were closely monitored for side effects if any, the onset of contraction, bleeding, cervical dilatation each time before insertion of each misoprostol. IAI since the insertion of the first intravaginal tablet of misoprostol was noted. The products of conception were examined for completeness.

The process was considered failed if abortion failed to occur within 24 hours of insertion of the first tablet of misoprostol without any additional intervention, incomplete if part or whole of the placenta was retained. If placenta was retained for more than 2 hours, surgical evacuation was done. In case of failure, another method medical or surgical was tried. $\mathrm{Rh}$ antibody was given to all $\mathrm{Rh}$ negative cases at the beginning of the procedure. Adverse effects were recorded from the time of mifepristone administration until 24 hours after the abortion.

A successful abortion was defined as complete expulsion without additional intervention within 24hrs. of the first dose of misoprostol. IAI and rates of adverse effects and complications were noted. An ultra-sonogram was performed $24 \mathrm{hrs}$. after the abortion to check for retained products of conception. Unless the patient requested sterilization procedure or had any complications, she was discharged 24 hours after the abortion and advised to come for followup after 6 weeks.

\section{OBSERVATIONS}

Majority of cases were between 21 and 30 years of age (Figure 1). The mean gravidity of the cases was 2.16 \pm 1.04 . The mean parity was $0.96 \pm 0.95$ (Figure 2). The mean gestational age was $17.52 \pm 2.02$ (Figure 3 ). The number of women having pregnancy with gestational age less than 16 weeks was $8(16 \%)$ and between 16 to 20 weeks was 42 (84\%) (Table 1). The reasons for requesting a termination of pregnancy included social causes 30 (60\%), economic constraints 12 (24\%), women having medical disorders 4 $(8 \%)$, and failed vasectomy $4(8 \%)$.

The mean IAI was $10.08 \pm 2.9 \mathrm{hrs}$.; $38(76 \%)$ women had a complete abortion within $\leq 12 \mathrm{hrs}$.; 48 (96\%) women had a successful complete abortion within $24 \mathrm{hrs}$. without additional intervention; $2(4 \%)$ women required surgical evacuation following the detection of retained products on the ultrasonogram; $96 \%$ of the fetuses were aborted dead and ensac. The mean dose of misoprostol required was 1.96 \pm 0.77 . No case required more than 3 doses of misoprostol (Table 4). The side effects observed were mainly nausea $(10 \%)$, vomiting $(12 \%)$, fever $(15 \%)$, abdominal cramps (12\%), diarrhea (2\%).

\section{DISCUSSION}

Labor induction abortion is effective throughout the second trimester. Compared with misoprostol alone, the combination of mifepristone and misoprostol results in a clinically significant reduction of $40 \%$ to $50 \%$ in time to abortion and can be used at all gestational ages. Misoprostol can be absorbed by many routes and has different pharmacokinetic properties in each route. It is absorbed the fastest via sublingual route. Orally absorption is slower than sublingual, but faster than vaginal/rectal routes. The vaginal or rectal route leads to a lower peak level of misoprostol, but has a much slower elimination curve.

Oral or sublingual administration leads to higher levels and faster onset of action, but will be associated with greater side effects (Predominantly fever and chills) ${ }^{[3]}$ There have been a number of randomized studies investigating the optimal dosage of misoprostol for second trimester abortion. Dickinson et al. found that 1) IUFD inductions complete much quicker than live abortions and 2) $400 \mathrm{mcg}$ of misoprostol administered vaginally every 6 hours was the optimal dose, providing nearly the best delivery characteristics but avoiding the side effects associated with higher dosing. ${ }^{[4]}$ Tang et al. did a randomized trial which showed vaginal misoprostol to be more effective than sublingual in second trimester abortion. ${ }^{[5]}$ Based on these data, the most evidence based dose of misoprostol for second trimester induction is $400 \mathrm{mcg}$ administered vaginally every $6 \mathrm{hrs}$.

In the present study, the IAI was $10.08 \pm 2.9 \mathrm{hrs}$. as compared to $6.72 \pm 2.26 \mathrm{hrs}$. in the study by Tripti et al. This may be because no initial loading dose was given and the dosage schedule was different ${ }^{(6)}$. Kapp et al. randomized women at 18 to 23 weeks gestation to mifepristone $24 \mathrm{hrs}$. before buccal misoprostol or misoprostol alone. The median abortion time with mifepristone was $10 \mathrm{hrs}$., a $45 \%$ reduction in time compared to the group without mifepristone. ${ }^{[7]}$ Nilas et al. compared cohorts of women using a 1- or 2-day interval between mifepristone and vaginal misoprostol at 17-22 weeks.

The women in the 1 day group had longer induction times, 9.8 versus $7.5 \mathrm{hrs}$. $(\mathrm{p}<0.1) ; 98 \%$ of the women in each group delivered within $24 \mathrm{hrs}$. of receiving misoprostol.[8] Increasing gestational age is also correlated with increased induction time when using mifepristone and misoprostol from 12 to 20 weeks. In our study too women with gestational age $<16$ weeks had a lower $(8.5 \pm .8 \mathrm{hrs}$.) IAI as compared to women with gestational age $\geq 16$ weeks $(10.52$ $\pm 2.87 \mathrm{hrs}$ ). Nullipara had a longer IAI of $10.6 \pm 2$. $8 \mathrm{hrs}$. as compared to parous women who had an IAI of $9.3 \pm 2.6 \mathrm{hrs}$. (Table 2).

Low rates of intervention for placental delivery are also reported for regimens using mifepristone and misoprostol. In a small study that noted the time to placental delivery after mifepristone abortion and buccal misoprostol, only $1(3 \%)$ of 32 women required placental removal.[7]

\section{CONCLUSION}

Mifepristone followed by repeated doses of misoprostol is an effective regimen available for second trimester abortion and has added advantage of being low cost, easily administrable, easily stored and has minimal side effects. Abortion of intact fetus and placenta is of help for fetal evaluation in case of fetal malformations. Further large randomized studies are needed on the need to evaluate the treatment of women with failed medical abortion after $24 \mathrm{hrs}$. and the use of the above 2 effective drugs in women with a scarred uterus.

\section{REFERENCES}

1. Boyd PA, Tondi F, Hicks NR, et al. Autopsy after termination of pregnancy for fetal anomaly: retrospective cohort study. BMJ 2004;328(7432):137.

2. Bygdeman M, Swahn ML. Progesterone receptor blockage. Effect on uterine contractility and early pregnancy. Contraception 1985 Jul;32(1):45-51.

3. Tang OS, Gemzell-Danielsson K, Ho PC. Misoprostol: Pharmacokinetic profiles, effects on the uterus and sideeffects. International Journal of Gynecology \& Obstetrics 2007;99(Suppl 2):S160-67. 
4. Dickinson JE, Evans SF. The optimization of intravaginal misoprostol dosing schedules in second trimester pregnancy termination. Am J Obstet Gynecol 2002 Mar;186(3):4704.

5. Tang OS, Schweer H, Lee SW, Ho PC. Pharmacokinetics of repeated doses of misoprostol. Hum Reprod 2009 Aug;24(8):18629.Epub 2009 Apr 23.

6. Tripti N, Namrata S. Misoprostol vs. mifepristone and misoprostol in second trimester termination of .pregnancy. J Obstet Gynecol India 2011;61(6):659-62.

7. Kapp N, Borgatta L, Stubblefield PG, Vragovic O, Moreno $\mathrm{N}$. Mifepristone in midtrimester medical abortion: a randomized controlled trial. Obstet Gynecol 2007;110:1304-10 (Evidence Grade: I).

8. Nilas L, Glavind-Kristensen M, Vejborg T, Knudsen UB. One or two day mifepristone-misoprostol interval for second trimester abortion. Acta Obstet Gynecol Scand 2007;86:1117-21 (Evidence Grade: I).

\begin{tabular}{|c|c|}
\hline Variable & $\begin{array}{c}\text { Mifepristone+Misoprostol } \\
{[\mathbf{N = 5 0}]}\end{array}$ \\
\hline $\begin{array}{c}\text { Age: } \\
\text { Mean in Years }\end{array}$ & $25.88 \pm 6.5$ years \\
\hline Minimum & 13 years \\
\hline Maximum & 37 years \\
\hline $\begin{array}{c}\text { Gravidity: } \\
\text { Mean }\end{array}$ & $2.16 \pm 1.04$ \\
\hline Minimum & 1 \\
\hline Maximum & 4 \\
\hline $\begin{array}{c}\text { Parity: } \\
\text { Mean }\end{array}$ & $0.96 \pm 0.95$ \\
\hline Minimum & 0 \\
\hline Maximum & 3 \\
\hline $\begin{array}{c}\text { Gestational Age: } \\
\text { Mean }\end{array}$ & $17.52 \pm 2.02$ \\
\hline Minimum & 14 \\
\hline Maximum & 20 \\
\hline Table 1: Demographic variables of the study population \\
\hline
\end{tabular}

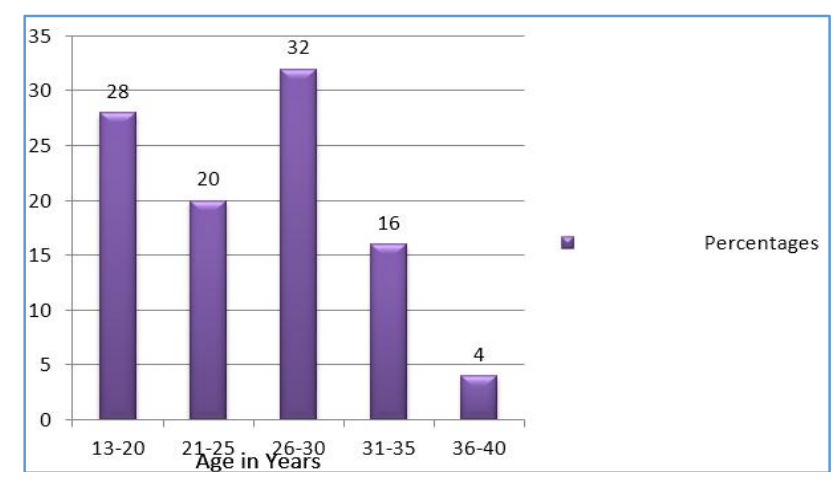

Fig. 1: Age of Clients Requesting Abortion

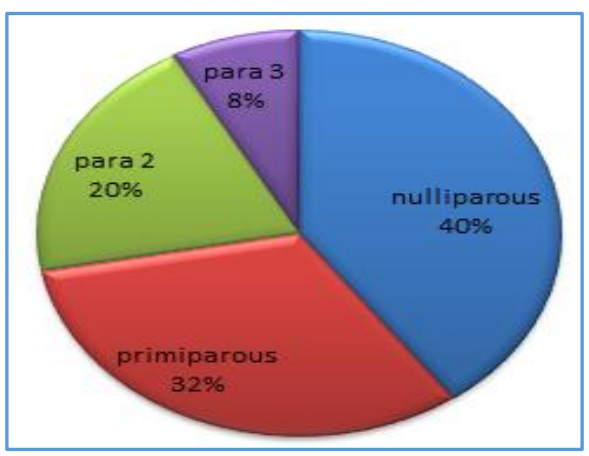

Fig. 2: Parity Status of Clients requesting Abortion

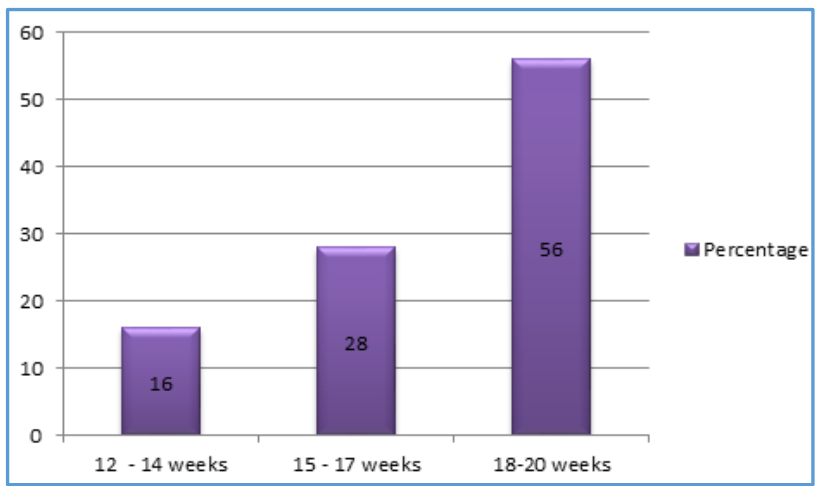

Fig. 3: Gestational Age at which Clients Requested Abortion

\begin{tabular}{|c|c|}
\hline Variable & $\begin{array}{c}\text { Induction to } \\
\text { abortion interval }\end{array}$ \\
\hline $\begin{array}{c}\text { Parity } \\
\text { Nullipara }\end{array}$ & $10.6 \pm 2.8 \mathrm{hrs}$ \\
\hline Parous & $9.3 \pm 2.6 \mathrm{hrs}$ \\
\hline $\begin{array}{c}\text { Pregnancy Duration } \\
<16 \text { weeks }\end{array}$ & $8.5 \pm 1.8 \mathrm{hrs}$ \\
\hline \multicolumn{2}{|c|}{$\geq 16$ weeks } \\
\hline $\begin{array}{c}\text { Table 2: Induction to abortion interval by parity and } \\
\text { pregnancy duration }\end{array}$ \\
\hline
\end{tabular}

\begin{tabular}{|c|c|c|}
\hline Sl. No & $\begin{array}{c}\text { I.A.I duration } \\
\text { in hours }\end{array}$ & N = 50 \\
\hline 1. & $0-5 \mathrm{hrs}$ & 0 \\
\hline 2. & $6-10 \mathrm{hrs}$ & $28(56 \%)$ \\
\hline 3. & $11-15 \mathrm{hrs}$ & $22(44 \%)$ \\
\hline Minimum & $6 \mathrm{hrs}$ & \\
\cline { 1 - 2 } Maximum & $15 \mathrm{hrs}$ & \\
\cline { 1 - 2 } Table 3: Distribution of cases according \\
to the induction abortion interval
\end{tabular}

\begin{tabular}{|c|c|}
\hline Variable & N = 50 \\
\hline $\begin{array}{c}\text { Successsful complete abortions within } \\
\text { 24 hrs without additional } \\
\text { intervention. }\end{array}$ & $48(96 \%)$ \\
\hline & $2(4 \%)$ \\
\hline $\begin{array}{c}\text { Surgical evacuation(incomplete } \\
\text { abortion) }\end{array}$ & $10.08 \pm 2.9 \mathrm{hrs}$ \\
\hline Induction to abortion interval (in hrs) & $38(76 \%)$ \\
\hline Complete abortion within $\leq 12 \mathrm{hrs}$ & $1.96 \pm 0.77$ \\
\hline $\begin{array}{c}\text { No of Misoprostol doses } \\
\text { Mean }\end{array}$ & 36 \\
\hline 1-2 doses & 14 \\
\hline 3-5 doses & \\
\hline Table 4: Outcome Measures \\
\hline
\end{tabular}

